\title{
Frequency Analysis for Prediction of Maximum Flood Discharge in Mahanadi River Basin
}

\author{
B. Panigrahi ${ }^{1}$, Dipsika Paramjita ${ }^{2 *}$, M. Giri ${ }^{3}$ and J. C. Paul ${ }^{1}$ \\ ${ }^{1}$ Department of Soil and Water Conservation Engineering, College of Agricultural \\ Engineering and Technology, Odisha University of Agriculture \& Tech., Bhubaneswar, \\ Odisha, India \\ ${ }^{2}$ KVK (OUAT), Sakhigopal, Puri, Odisha, India \\ ${ }^{3}$ Department of Soil and Water Conservation Engineering, College of Agricultural \\ Engineering and Technology, Odisha University of Agriculture \& Tech., Bhubaneswar, \\ Odisha, India \\ *Corresponding author
}

\begin{abstract}
A B S T R A C T
Daily discharge data for 30 years of five gauging stations of Mahanadi river basin of Odisha, India were collected and analysed for prediction of peak flood discharge. The five gauging stations under the study are Kantamal, Kesinga, Salebhata, Sundargarh and Tikarapara. Using the daily data, peak daily discharge data of ach station of each year were found out. The peak daily discharge data of various stations were analyzed by "FLOOD" software and the values at different probability of exceedences (PE) by 12 different probability distributions like Normal, Log-Normal (3p), Pearson, Log-Pearson, Weibull, Generalized Pareto, Extreme Value Type III, Gumble-maximum, Gumble-minimum, Generalised Extreme Value, Exponential and Gamma were predicted. The best fit distribution was decided by chi-square test as well as 2 other statistical tests i.e. root mean square error (RMSE) and mean absolute relative error (MARE). Based on the lowest values of statistical parameters of Chi square, RMSE and MARE, best fit probability distributions of each station was decided. Generalised Pareto distribution for Kantamal and Kesinga, Log-Pearson in Salebhata and Sundargarh station and Generalised Extreme Value in Tikarapara station are found to be the best fit probability distribution. Values of discharge at different probability levels were predicted by the best fit distributions for each station. Values of peak discharge at $20 \%$ PE level as predicted by the best fit distributions for Kantamal, Kesinga, Salebhata, Sundargarh and Tikarapara are 14964.51, 13286.95, $4171.32,3106.23$ and $28057.23 \mathrm{~m}^{3} / \mathrm{s}$, respectively. These values may be considered for design of hydraulic structures in respective stations.
\end{abstract}

\section{Keywords}

Stage, Discharge, Flood, Probability distribution function, Probability of exceedence, FLOOD software

\section{Article Info}

Accepted:

26 July 2020

Available Online:

10 August 2020

\section{Introduction}

For proper planning and design of hydraulic structures like dams, spillways, culverts, etc., a reliable estimation of peak discharge for a given return period at the site of interest is necessary. The peak discharge can be effectively determined by fitting of 
probability distributions to the series of recorded annual maximum discharge data through flood frequency analysis (Vivekanandan, 2015).

A number of probability distributions are commonly used in flood frequency analysis. According to the theory of probability distributions, Exponential, Gamma, and Pearson are called as gamma family of distributions whereas Extreme Value TypeIII, Generalized Extreme Value and Generalized Pareto GPA are called as extreme value family of distributions. Generally, method of moments (MoM) for its simplicity is used for determination of parameters of the probability distribution. In view of the above, MoM is popularly used for determination of parameters of probability distributions. Formal statistical procedures involving goodness-of-fit is used to determine a particular distribution for a region or country. For quantitative assessment on maximum flood discharge within the recorded range, root mean square error and mean absolute error tests are applied (Vivekanandan, 2015).

Tao et al., (2002) proposed a systematic assessment procedure to compare the performance of different probability distributions in order to identify an appropriate model that could provide the most accurate extreme rainfall estimates at a particular site. Nine probability models such as Beta-K (BEK), Beta-P (BEP), Generalized Extreme Value (GEV), Generalized Normal (GNO), Generalized Pareto (GPA), Gumbel (GUM), Log-Pearson Type III (LP3), Pearson Type III (PE3), and Wakeby (WAK) distributions were compared for their descriptive and predictive abilities to represent the distribution of annual maximum rainfalls. The suggested methodology was applied to 5-minute and 1-hour annual maximum rainfall series from a network of 20 rain gauges in Southern Quebec region. On the basis of graphical and numerical comparisons, it was found that the WAK, GNO and GEV models could provide the most accurate extreme rainfall estimates. However, the GEV was recommended as the most suitable distribution due to its theoretical basis for representing extreme - value process and its relatively simple parameter estimation.

Topaloglu (2002) reported that the frequency analysis of extreme values of a sequence of hydrologic events has long been an essential part of the design of hydraulic structures. He made a statistical comparison of currently popular probability models such as Gumbel, log-logistic, Pearson Type III, Log-Pearson Type III and Log-Normal (3p) distributions to the series of annual instantaneous flood peaks and annual peak daily precipitation for 13 flow gauging and 55 precipitation gauging stations in the Seyhan basin, respectively. The parameters of the distributions were estimated by the methods of moments and probability weighted moments. According to the evaluations of Chi-square tests, Gumbel for both flow and precipitation stations in the Seyhan river basin were found to be the best models.

Lee (2005) studies the rainfall distribution characteristics of Chia-Nan plain area by using different statistical analyses such as normal distribution, Log-Normal distribution, Extreme Value Type I distribution, Pearson Type III distribution, and Log-Pearson Type III distribution. Results showed that the LogPearson Type III distribution performed the best in probability distribution, occupying $50 \%$ of the total station number, followed by the Log-Normal distribution and Pearson Type III distribution, which accounts for $19 \%$ and $18 \%$ of the total station numbers, respectively.

Abida and Ellouze (2007) studied on regional flood frequency distributions for different 
zones of Tunisia. The distributions which represent five of the most frequently used distributions in the analysis of hydrologic extreme variables are: (i) Generalized Extreme Value (GEV), (ii) Pearson Type III (P3), (iii) Generalized Logistic (GLO), (iv) Generalized Normal (GN), and (v) Generalized Pareto (GPA) distributions. Northern Tunisia was shown to be represented by the GEV distribution while the GLO distribution gave the best fit in central/southern Tunisia.

Adeboye and Alatise (2007) did the statistical analysis of 18-year streamflow record of river Osun at Apoje gauging station, Nigeria. They fitted the peak discharges to the three major statistical distributions namely normal, LogNormal and Log-Pearson Type III while seven plotting positions of Hazen, Weibull, Blom, Cunnane, California, Gringorton and Chegodajev were used in determining their probabilities of exceedance. Weibull's plotting position combined with normal distribution gave the highest fit, most reliable and accurate predictions of the flood in the study area having the coefficient of determination $\mathrm{R}^{2}$ and root mean square error of 0.99 and $35.09 \mathrm{~m}^{3} / \mathrm{s}$, respectively.

The generalized extreme value distribution was reported to be the best distribution amongst all other distributions to forecast the maximum flood discharge in most of the gauging stations in Bangladesh. Comparisons of distributions were based upon the root mean square deviation test, the probability plot correlation coefficient and L-moment ratio diagrams (Karim and Chowdhury, 2009).

Olofintoye et al., (2009) studied the peak daily rainfall distribution characteristics in Nigeria by using different statistical analyses such as Gumbel, Log-Gumbel, Normal, LogNormal, Pearson and Log-Pearson distributions. They selected 20 stations having annual rainfall data of fifty-four years to perform frequency analysis. They subjected the predicted values for goodness of fit tests such as chi-square, Fisher's test, correlation coefficient and coefficient of determination. The Log-Pearson Type III distribution performed the best by occupying $50 \%$ of the total station number, while Pearson Type III performed second best by occupying $40 \%$ of the total stations and lastly Log-Gumbel occupied $10 \%$ of the total stations.

Ewemoje and Ewemooje (2011) discussed Normal, Log-Normal, and log-Pearson type 3 distributions for modelling at-site annual maximum flood flows for Ona River under Ogun-Osun river basin, Nigeria using the Hazen, Weibull and California plotting positions. Comparing the probability distributions, Log-Pearson Type III distribution with the least absolute differences for all the plotting positions was the best distribution among the three study location.

Garba et al., (2013) performed frequency analysis by fitting probability distribution functions of Normal, Log-Normal, LogPearson type III and Gumbel to the discharge variability of Kaduna river at Kaduna South Water Works. They used the KolmongonovSmirnov (K-S) goodness-of-fit test to check whether the mean annual discharge variability of the river basin is consistent with a regional GEV distribution for the site. They observed that at selected level of significance of $\alpha=$ $1 \%, \alpha=5 \%$ and $\alpha=10 \%$, all the four theoretical distribution functions were acceptable.

Khan (2013) prepared frequency distribution study on maximum monthly flood data in Narmada river at Garudeshwar station. He proposed the Normal, Log-Normal, LogPearson type III and Gumbel extreme value type I and tested together with their single 
distributions to identify the optimal model for maximum monthly flood analysis. The results indicated that Normal distribution was better than the other distributions in modelling maximum monthly flood magnitude at Garudeshwar station in Narmada River. Hence he derived frequency curve at Garudeshwar station using Normal distribution method.

Solomon and Prince (2013) carried out the study on Osse river with flow measurements at Iguoriakhi and conducted flood frequency analysis of the river (Osse River) using Gumbel's distribution which is one of the popular probability distribution used to model stream flow. They used Gumbel's distribution to model the annual maximum discharge of the river for a period of 20 years (1989 to 2008). Using this distribution at return periods of $2,5,10,25,50,100,200$ and 400 years, the expected estimated discharges obtained were 2156.61, 2436.24, 2621.38, 2855.31, $3028.85,3201.11,3372.74$ and $3544.05 \mathrm{~m}^{3} / \mathrm{s}$, respectively. These values of discharges are useful for storm management in the study area.

Deb and Choudhury (2015) studied frequency distribution of maximum annual flood data in Barak River at Annapurna Ghat (A.P.) station using the Normal, Log-Normal, Log-Pearson type III and Gumbell extreme value type I to identify the optimal model for maximum annual flood analysis. The results indicated that Normal distribution was better than the other distributions in modeling maximum annual flood magnitude at A.P Ghat station in Barak River.

Vivekanandan (2015) discussed how flood frequency analysis by fitting of probability distributions to the recorded annual maximum discharge data required for estimation of maximum flood discharge for a given return period for planning, design and management of hydraulic structures for the project. He adopted Gamma and Extreme value family of probability distributions for flood frequency analysis. The study showed that the Gamma distribution is found to be the best in the estimation of maximum flood discharge. A number of other researchers have found the Gamma and Extreme value family of probability distributions as the best for flood frequency analysis for estimation of maximum flood discharge for a given return period (Khosravi et al., 2012; Garba et al., 2013; Khatua et al., 2014).

In Odisha the Mahanadi is the largest river with an extensive delta responsible for most of the devastating flood hazards in the coastal zone. Over a period of 146 years between 1855 and 2000 there were 28 high flood years, 57 medium flood years and 48 low flood years (Mishra, 2008). There is a need to study the peak flood magnitude at different probability of exceedences by different probability distribution functions.

\section{Materials and Methods}

\section{Study Area}

The present study is undertaken for the middle reach of the Mahanadi basin. The Mahanadi basin extends over the states of Chhattisgarh and Odisha and comparatively smaller portions of Jharkhand, Maharashtra and Madhya Pradesh, draining an area of $1,41,589$ sq.km which is nearly $4.3 \%$ of the total geographical area of the country. The catchment area of Jharkhand, Madhya Pradesh, Chattisgarh, Maharashtra and Odisha are 126, 107, 75229, 238 and 65889 sq. km, respectively.

The geographical extent of the basin lies between $80^{\circ} 28^{\prime}$ and $86^{\circ} 43^{\prime}$ east longitudes and $19^{\circ} 8^{\prime}$ and $23^{\circ} 32^{\prime}$ north latitudes. The basin has maximum length and width of 587 
$\mathrm{km}$ and $400 \mathrm{~km}$, respectively. It is bounded by the Central India hills on the north, by the Eastern Ghats on the south and east and by the Maikala range on the west.

\section{The Mahanadi River System}

The river Mahanadi is one of the major interstate east flowing rivers in peninsular India. It originates at an elevation of about $442 \mathrm{~m}$. above mean sea level near Farsiya village in Dhamtari district of Chattisgarh. During the course of its traverse, it drains fairly large areas of Chhatisgarh and Odisha and comparatively small area in the state of Jharkhand and Maharashtra. The total length of the river from its origin to confluence of the Bay of Bengal is about $851 \mathrm{~km}$, of which, $357 \mathrm{~km}$ is in Chattisgarh and the balance 494 $\mathrm{km}$ in Odisha. During its traverse, a number of tributaries join the river on both the flanks. There are 14 major tributaries of which 12 numbers are joining upstream of Hirakud reservoir and 2 numbers downstream of it. On the left bank, six tributaries namely the Seonath, the Hasdeo, the Mand, the Ib, the Kelo and Borai drain into main channel upstream of Hirakud reservoir. Fig. 1 represents the view of the Mahanadi river basin.

The Mahanadi river basin has the outlet at Mundali near Cuttack (Odisha). The drainage system upstream of Hirakud reservoir is more extensive on the left bank of Mahanadi as compared to that on the right bank. The three major tributaries namely the Seonath and the $\mathrm{Ib}$ on the Left Bank and the Tel on the Right Bank together constitute nearly $46.63 \%$ of the total catchment area of the river Mahanadi. The Seonath, which is the largest tributary of Mahanadi, drains three districts of Chhatisgarh namely Durg, Rajnandgaon and Bilaspur. The Tel, which is the second largest tributary of Mahanadi River drains four districts of Odisha namely Koraput,
Kalahandi, Bolangir and Phulbhani. The Ib, which is the third largest tributary of Mahanadi, drains Raigarh district of Chhatisgarh and two districts of Odisha, namely Sundergarh and Sambalpur. Below the dam, the Mahanadi turns south along a tortuous course, piercing the Eastern Ghats through a forest-clad gorge. Bending east, it enters the Odisha plains near Cuttack and enters the Bay of Bengal at False Point by several channels.

Numerous dams, irrigation projects, and barrages (barriers in the river to divert flow or increase depth) are present in the Mahanadi river basin: the most prominent of which is Hirakud dam. It is the longest earthen dam in the world; it remains the largest reservoir in Asia with a surface area of 746 sq. $\mathrm{km}$ and a live storage capacity of $5.37 \mathrm{x} 109 \mathrm{~m}^{3}$. Approximately 65 percent of the basin is upstream from the dam. The average annual discharge of the river system is $1,895 \mathrm{~m}^{3} / \mathrm{sec}$, with a maximum of $6,352 \mathrm{~m}^{3} / \mathrm{sec}$ during the monsoon. Minimum discharge is $759 \mathrm{~m}^{3} / \mathrm{s}$ and occurs during the months October.

\section{Challenges faced in the basin}

Mahanadi is the largest river in Odisha with an extensive delta responsible for most of the devastating flood hazards in the coastal zone. Because of a large number of distributaries, the flood discharge at Naraj implies flood in most of the distributaries remaining downstream. Over a period of 146 years between 1855 and 2000 there were 28 high flood years, 57 medium flood years and 48 low flood years. The recurrence interval of a high flood in the Mahanadi is 5 years and that of a medium and low flood is 3 years. The Hirakud dam was made to alleviate the problem of flood and since then it is serving the purpose to a large extent but possibly will not in the coming future owing to the serious problem of siltation which accounts for the 
reduction in its volumetric storage capacity. The inhabited inner basin Chhattisgarh plain and KBK (Koraput, Bolangir, Kalahandi districts) in western Odisha at the boundary of Chattisgarh and Odisha suffers frequent droughts whereas the fertile deltaic area has been wrecked by repeated floods (Mishra, 2008).

\section{Gauge-Discharge Stations under Study}

The central as well as state governments carry out hydrological observations. The Central Water Commission maintains 20 gauge discharge sites in the basin. At 14 of these stations, sediment observations are also made. Number of flood forecasting stations is 4 . In the present study, five gauge-discharge stations of middle reach of Mahanadi river basin is considered. These are Tikarpara, Sundergarh, Salebhata, Kesinga and Kantamal.

\section{Statistical Analysis}

Table 1 represents variation of peak daily discharge of different stations. Data of peak daily discharge of all these 5 stations were collected from the office of the Central water Commission for 23 years (1990-91 to 201213).

\section{Fitting the Probability Distribution}

The peak daily discharge data of various stations were analyzed by "FLOOD" software and the values at different probability of exceedences (PE) by different probability distributions like Normal, Log-Normal (3p), Pearson, Log-Pearson, Weibull, Generalized Pareto, Extreme Value Type III, Gumblemaximum, Gumble-minimum, Generalised Extreme Value, Exponential and Gamma were predicted. The variation of peak daily discharge at different probability of exceedence levels (ranging from 10 to $90 \%$ ) by different distributions is shown in Figs. 2 to 6 for Kantamal, Kesinga, Salebhata, Sundargarh and Tikarapara, respectively.

\section{Testing the goodness of fit}

The goodness of fit test for the probability distributions was done by root mean square error (RMSE) and mean absolute error (MAE). These two errors were calculated for each distribution.

\section{Root mean square error}

The root-mean-square error (RMSE) is used to calculate how much actual observed value deviate from predicted value. RMSE is a good measure of accuracy. The RMSE between the predicted and observed stage and discharge were determined using the equation given by (Laogue and Green, 1991; Panigrahi and Panda, 2003) and is expressed as

$$
\mathrm{RMSE}=\sqrt{\sum_{i=1}^{9} \frac{\left(O_{i}-P_{i}\right)^{2}}{n}}
$$

Where, RMSE is root mean square error value, $P$ is predicted value, $O$ is observed value, $n$ is number of data point i.e. 9 and summation is done from $\mathrm{i}=1$ to 9 i.e. 10 to 90\% probability level.

The unit of RMSE for stage and discharge are $\mathrm{m}$ and $\mathrm{m}^{3} / \mathrm{s}$, respectively.

\section{Mean absolute error}

In statistics, the mean absolute error (MAE) is a quantity used to measure how close the actual observed values are to the predicted values. The mean absolute error is given as (Panigrahi and Panigrahi, 2016):

$$
M A E=\frac{1}{n} \sum_{i=1}^{9}|O i-P i|
$$

Where, MAE is mean absolute error value, $O$ is observed value, $P$ is predicted value, $n$ is 
number of data point i.e. 9 and summation is done from $\mathrm{i}=1$ to 9 i.e. 10 to $90 \%$ probability level.

The unit of MAE for stage and discharge are $\mathrm{m}$ and $\mathrm{m}^{3} / \mathrm{s}$, respectively.

\section{Weibull's distribution}

Observed values of stage and discharge at 10 to $90 \%$ PE levels were predicted by Weibull's distribution.

Weibull's distribution or simply called as Weibull's plotting position is expressed as (Panigrahi and Panigrahi, 2014):

$P=\frac{m}{N+1} \times 100$

Where, $P$ is probability of exceedence (PE) in percent, $m$ is rank number when data are arranged in descending order and $N$ is total number of data in the series.

The values of RMSE and MAE calculated for each distribution for discharge of all the stations are presented in Table 2.

\section{Identification of best fit probability distribution}

Based on the lowest values of statistical parameters of RMSE and MAE, best fit probability distributions of both stage and discharge of each station were decided.

The identified best fit probability distributions of discharge data of different stations are presented in Table 3.

Using these best fit probability distributions, values of discharge at different probability levels (PE) ranging from 10 to $90 \%$ were predicted and are shown in Table 4 for discharge data.

\section{Results and Discussion}

\section{Statistical analysis of daily discharge data}

The daily discharge data were collected from Central Water Commission, Bhubaneswar. The peak daily stage and discharge of each year of each station were found out from these data. Table 1 shows that amongst all the years Kantamal has the highest peak discharge of $20000.00 \mathrm{~m}^{3} / \mathrm{s}$ which was obtained in 2008-2009, Kesinga has the highest peak discharge of $21192.00 \mathrm{~m}^{3} / \mathrm{s}$ which was obtained in 2006-2007, Salebhata has the highest peak discharge of 7916.00 $\mathrm{m}^{3} / \mathrm{s}$ which was obtained in 2003-2004 and Sundargarh has the highest peak discharge of $10404.00 \mathrm{~m}^{3} / \mathrm{s}$ which was obtained in 19981999. Similarly Table 1 indicates that amongst all the years, Tikarapara has the highest peak discharge of $31510.00 \mathrm{~m}^{3} / \mathrm{s}$ which was obtained in 1995-1996.

From Table 1 it can be concluded that the highest peak discharge for each station are obtained in the same year. It varies from station to station like in Kantamal it is obtained in 2008-2009, Kesinga in 20062007, Salebhata in 2003-2004, Sundargarh in 1998-1999 and Tikarapara in 1995- 1996, respectively. The peak daily discharge amongst all the years vary from 891.47 to $20000.00 \mathrm{~m}^{3} / \mathrm{s}$ for Kantamal, 600.00 to $21192.00 \mathrm{~m}^{3} / \mathrm{s}$ for Kesinga, 114.00 to 7916.00 $\mathrm{m}^{3} / \mathrm{s}$ for Salebhata, 962.00 to $10404.00 \mathrm{~m}^{3} / \mathrm{s}$ for Sundargarh and 156.90 to $33800.00 \mathrm{~m}^{3} / \mathrm{s}$ for Tikarapara, respectively.

\section{Fitting the Probability Distribution}

The peak daily discharge data of various stations were analyzed by "FLOOD" software and the values at different probability of exceedences (PE) by different probability distributions like Normal, Log-Normal (3p), Pearson, Log-Pearson, Weibull, Generalized 
Pareto, Extreme Value Type III, Gumblemaximum, Gumble-minimum, Generalised Extreme Value, Exponential and Gamma were predicted.

The variation of peak daily discharge at different probability of exceedence levels (10 to $90 \%$ ) by different probability distributions like Normal, Log-Normal (3p), Pearson, LogPearson, Weibull, Generalized Pareto, Extreme Value Type III, Gumble-maximum, Gumble-minimum, Generalised Extreme Value, Exponential and Gamma of Kantamal station are shown in Fig. 2 for Kantamal. The same are presented for Kesinga, Salebhata, Sundargarh and Tikarapara in Figs. 3, 4, 5 and 6 , respectively. The values of discharge are found gradually to decrease from $10 \% \mathrm{PE}$ level to $90 \%$ PE level for all distributions and for all stations. The peak daily discharge value is the highest at $10 \% \mathrm{PE}$ level and the lowest in $90 \%$ PE level for each station.

At $10 \%$ PE, the highest value of peak daily discharge for Kantamal is obtained by LogNormal and the lowest value by Gumbleminimum. However, the same distributions do not give the highest values for other PE levels. At $20 \%$ PE level, the highest and lowest values are obtained by Generalised Pareto and Gumble-maximum, respectively. For Kesinga at $10 \% \mathrm{PE}$, discharge value is the highest at Exponential and the lowest at Gumble-minimum. Similarly at $10 \%$ PE for Salebhata, Log-Normal and Gumbleminimum give the highest and lowest value, respectively and it also vary for other $\mathrm{PE}$ levels. Sundargarh had the highest and lowest peak daily discharge at $10 \%$ PE level by Exponential and Log-Normal, respectively and whereas the highest and lowest values of discharge at $20 \%$ PE level for Sundargarh was given by Normal and Log-Pearson, respectively. But for Tikarapara, Log-Normal gives the highest peak daily discharge value for 10, 20 and 30\% PE level continuously and then the trend changed at $40 \% \mathrm{PE}$ with the highest value by Generalised Pareto and so on. Log-Pearson gives the lowest value for 10 and $20 \%$ PE level continuously and after that it has also changed trend for which at $30 \%$ PE, the lowest was at Gumble-maximum.

\section{Testing the Goodness of Fit}

The goodness of fit test for the probability distributions was done by root mean square error (RMSE) and mean absolute error (MAE). Table 2 represents the values of RMSE and MAE of discharge by different probability distribution functions for Kantamal, Kesinga, Salebhata, Sundargarh and Tikarapara station. Exponential distribution for Kantamal, Gumble- minimum for Kesinga, Salebhata and Sundargarh and Log-Pearson for Tikarapara show the highest RMSE and MAE values for discharge. Similarly Generalised Pareto for Kantamal and Kesinga, Log-Pearson for Salebhata and Sundargarh and Generalised Extreme Value for Tikarapara are found to have the lowest RMSE and MAE values for discharge.

\section{Identification of Best Fit Probability Distribution}

Identification of best fit probability distribution is done from the values of RMSE and MAE. The lowest value of RMSE and MAE of any station will be the best fit probability distribution function for discharge in that station.

Table 3 shows the best fit probability distribution for discharge at various stations. From Table 3 it can be concluded that, Generalised Pareto in Kantamal and Kesinga station, Log-Pearson in Salebhata and Sundargarh station and Generalised Extreme Value in Tikarapara station are found to be the best fit probability distribution. 
Table.1 Variation of peak daily discharge of different stations

\begin{tabular}{|c|c|c|c|c|c|}
\hline Station & Kantamal & Kesinga & Salebhata & Sundargarh & Tikarapara \\
\hline Year & $\begin{array}{c}\text { Peak discharge } \\
\qquad\left(\mathrm{m}^{3} / \mathbf{s}\right)\end{array}$ & $\begin{array}{l}\text { Peak discharge } \\
\qquad\left(\mathrm{m}^{3} / \mathbf{s}\right)\end{array}$ & $\begin{array}{c}\text { Peak discharge } \\
\left(\mathrm{m}^{3} / \mathrm{s}\right)\end{array}$ & $\begin{array}{c}\text { Peak discharge } \\
\qquad\left(\mathrm{m}^{3} / \mathbf{s}\right)\end{array}$ & $\begin{array}{l}\text { Peak discharge } \\
\qquad\left(\mathrm{m}^{3} / \mathrm{s}\right)\end{array}$ \\
\hline 1990-1991 & 13633.00 & 15000.00 & 1629.00 & 1350.00 & 6535.60 \\
\hline 1991-1992 & 10560.00 & 9969.00 & 1259.90 & 4591.00 & 20067.83 \\
\hline 1992-1993 & 16263.00 & 17568.00 & 3250.00 & 1639.00 & 30500.00 \\
\hline 1993-1994 & 5400.00 & 2858.00 & 1341.00 & 962.00 & 31500.00 \\
\hline 1994-1995 & 11659.00 & 9734.00 & 3577.20 & 5780.00 & 20435.00 \\
\hline 1995-1996 & 8692.00 & 6608.00 & 2346.00 & 800.30 & 31510.00 \\
\hline 1996-1997 & 1890.60 & 2926.00 & 398.30 & 6341.00 & 23121.00 \\
\hline 1997-1998 & 11982.39 & 8143.00 & 2428.00 & 1306.00 & 11930.00 \\
\hline 1998-1999 & 891.47 & 600.00 & 560.00 & 10404.00 & 23000.00 \\
\hline $1999-2000$ & 1974.00 & 1368.00 & 1935.00 & 2030.00 & 25000.00 \\
\hline 2000-2001 & 3425.00 & 2452.00 & 114.00 & 2000.30 & 13249.00 \\
\hline $2001-2002$ & 12770.00 & 12822.00 & 3225.03 & 3200.00 & 4774.76 \\
\hline $2002-2003$ & 2900.00 & 1990.89 & 1545.40 & 1664.00 & 26700.00 \\
\hline 2003-2004 & 12915.07 & 8908.43 & 7916.00 & 1150.00 & 12305.64 \\
\hline 2004-2005 & 9007.81 & 4917.02 & 1146.58 & 1112.36 & 25062.00 \\
\hline $2005-2006$ & 11030.05 & 8120.83 & 1924.00 & 878.52 & 17744.45 \\
\hline 2006-2007 & 17500.00 & 21192.00 & 4681.36 & 1356.20 & 19000.00 \\
\hline $2007-2008$ & 12856.50 & 10941.65 & 2419.44 & 1417.86 & 29000.00 \\
\hline 2008-2009 & 20000.00 & 20124.00 & 3271.15 & 1346.18 & 15789.35 \\
\hline 2009-2010 & 11797.73 & 4607.20 & 4330.68 & 1674.51 & 20565.49 \\
\hline 2010-2011 & 10944.47 & 8764.63 & 787.80 & 1196.31 & 17750.50 \\
\hline 2011-2012 & 3267.63 & 2900.00 & 4552.15 & 3098.79 & 13575.05 \\
\hline 2012-2013 & 3466.36 & 2688.32 & 4880.27 & 1419.81 & 30400.00 \\
\hline Mean & 9340.26 & 8052.30 & 2587.75 & 2466.01 & 21162.34 \\
\hline
\end{tabular}

Table.2 Values of statistical parameters of discharge by different probability distribution functions

\begin{tabular}{|c|c|c|c|c|c|c|c|c|c|c|}
\hline \multirow[t]{3}{*}{ Probability distribution function } & \multicolumn{10}{|c|}{ Station } \\
\hline & \multicolumn{2}{|c|}{ Kantamal } & \multicolumn{2}{|c|}{ Kesinga } & \multicolumn{2}{|c|}{ Salebhata } & \multicolumn{2}{|c|}{ Sundargarh } & \multicolumn{2}{|c|}{ Tikarapara } \\
\hline & RMSE & MAE & RMSE & MAE & RMSE & MAE & RMSE & MAE & RMSE & MAE \\
\hline Normal & 0.071 & 0.058 & 0.065 & 0.056 & 0.051 & 0.042 & 0.149 & 0.124 & 0.039 & 0.033 \\
\hline Log-normal & 0.105 & 0.084 & 0.058 & 0.042 & 0.058 & 0.050 & 0.094 & 0.075 & 0.122 & 0.108 \\
\hline Pearson & 0.071 & 0.058 & 0.049 & 0.038 & 0.028 & 0.022 & 0.099 & 0.082 & 0.036 & 0.033 \\
\hline Log-pearson & 0.081 & 0.067 & 0.047 & 0.035 & 0.027 & 0.067 & 0.057 & 0.048 & 0.217 & 0.163 \\
\hline Weibull & 0.093 & 0.076 & 0.049 & 0.037 & 0.028 & 0.023 & 0.112 & 0.094 & 0.042 & 0.344 \\
\hline Generalised Pareto & 0.061 & 0.050 & 0.037 & 0.031 & 0.034 & 0.028 & 0.069 & 0.056 & 0.100 & 0.084 \\
\hline Extreme Value Type-III & 0.067 & 0.056 & 0.045 & 0.036 & 0.027 & 0.023 & 0.099 & 0.083 & 0.034 & 0.029 \\
\hline Gumble Maximum & 0.108 & 0.089 & 0.054 & 0.040 & 0.031 & 0.024 & 0.123 & 0.105 & 0.072 & 0.062 \\
\hline Gumble Minimum & 0.065 & 0.051 & 0.101 & 0.089 & 0.090 & 0.076 & 0.182 & 0.149 & 0.050 & 0.040 \\
\hline Generalised Extreme Value & 0.070 & 0.057 & 0.050 & 0.039 & 0.029 & 0.022 & 0.108 & 0.093 & 0.029 & 0.025 \\
\hline Exponential & 0.114 & 0.096 & 0.061 & 0.049 & 0.078 & 0.064 & 0.119 & 0.096 & 0.172 & 0.149 \\
\hline Gamma & 0.110 & 0.091 & 0.057 & 0.045 & 0.035 & 0.028 & 0.110 & 0.093 & 0.061 & 0.052 \\
\hline
\end{tabular}


Table.3 Best fit distribution for discharge data at various stations

\begin{tabular}{|c|c|}
\hline Station & Best fit distribution \\
\hline Kantamal & Generalised Pareto \\
\hline Kesinga & Generalised Pareto \\
\hline Salebhata & Log Pearson \\
\hline Sundargarh & Log Pearson \\
\hline Tikarapara & Generalised Extreme Value \\
\hline
\end{tabular}

Table.4 Daily discharge $\left(\times 10 \mathrm{~m}^{3} / \mathrm{s}\right)$ of various stations at different probability of exceedence $(\%)$ by best fit distribution

\begin{tabular}{|l|c|c|c|c|c|c|c|c|c|}
\hline \multirow{2}{*}{ Station } & \multicolumn{8}{|c|}{ Probability of exceedence, \% } \\
\cline { 2 - 11 } & $\mathbf{1 0}$ & $\mathbf{2 0}$ & $\mathbf{3 0}$ & $\mathbf{4 0}$ & $\mathbf{5 0}$ & $\mathbf{6 0}$ & $\mathbf{7 0}$ & $\mathbf{8 0}$ & $\mathbf{9 0}$ \\
\hline Kantamal & 17.02 & 14.96 & 12.99 & 11.07 & 9.19 & 7.34 & 5.52 & 3.71 & 1.93 \\
\hline Kesinga & 16.96 & 13.29 & 10.66 & 8.55 & 6.75 & 5.17 & 3.75 & 2.45 & 1.25 \\
\hline Salebhata & 5.21 & 4.17 & 3.42 & 2.81 & 2.29 & 1.82 & 1.38 & 0.96 & 0.53 \\
\hline Sundargarh & 4.67 & 3.11 & 2.40 & 1.97 & 1.66 & 1.43 & 1.24 & 1.06 & 0.89 \\
\hline Tikarapara & 31.04 & 28.06 & 25.65 & 23.45 & 21.30 & 19.07 & 16.62 & 13.68 & 9.51 \\
\hline
\end{tabular}

Fig.1 View of the Mahanadi River basin

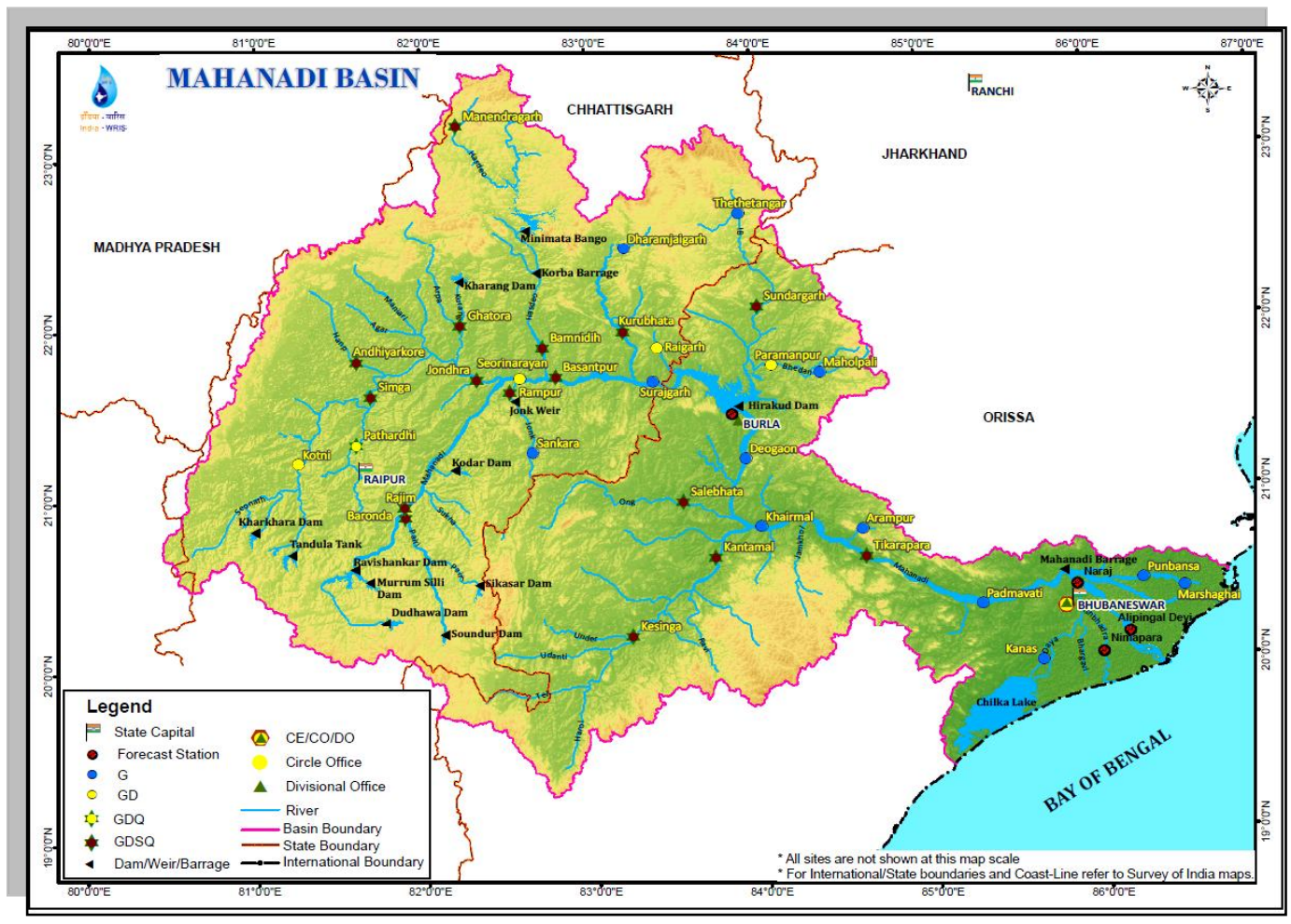


Fig.2 Variation of peak daily discharge at different PE levels by different distributions (Kantamal)

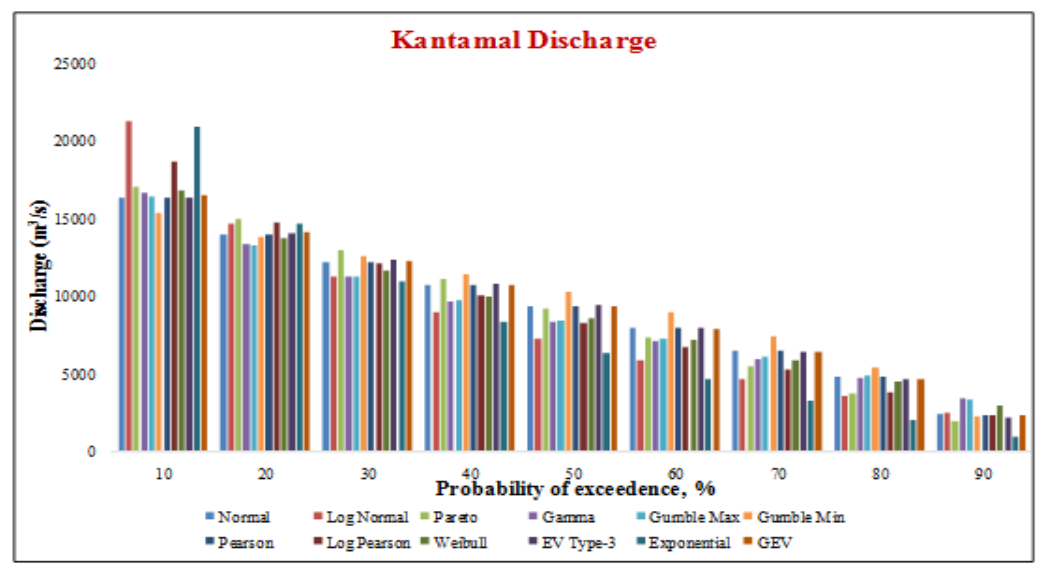

Fig.3 Variation of peak daily discharge at different PE levels by different distributions (Kesinga)

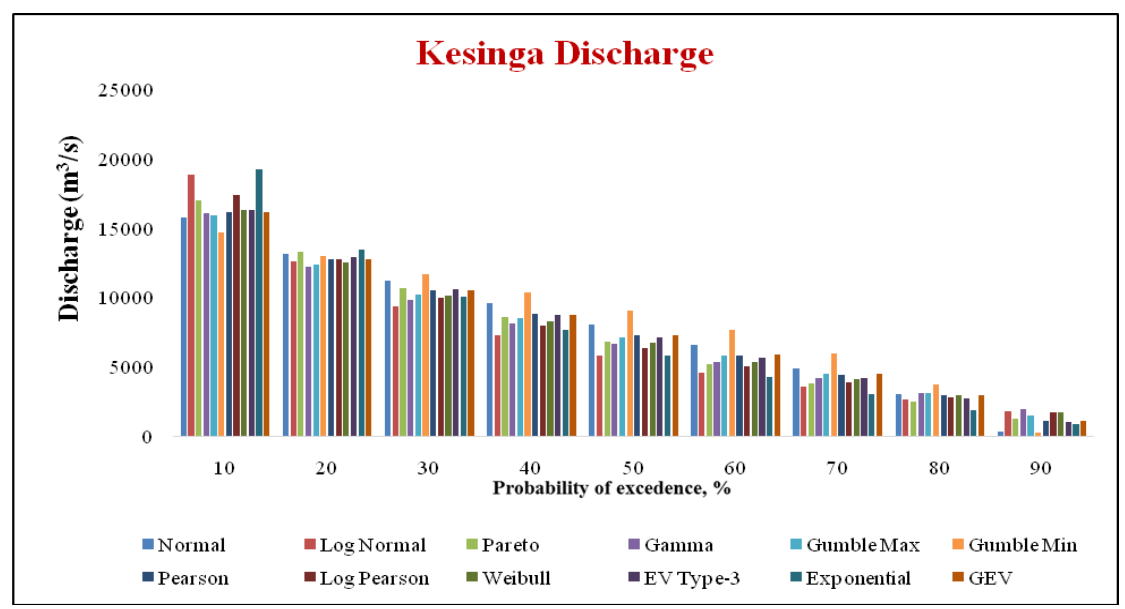

Fig.4 Variation of peak daily discharge at different PE levels by different distributions (Salebhata)

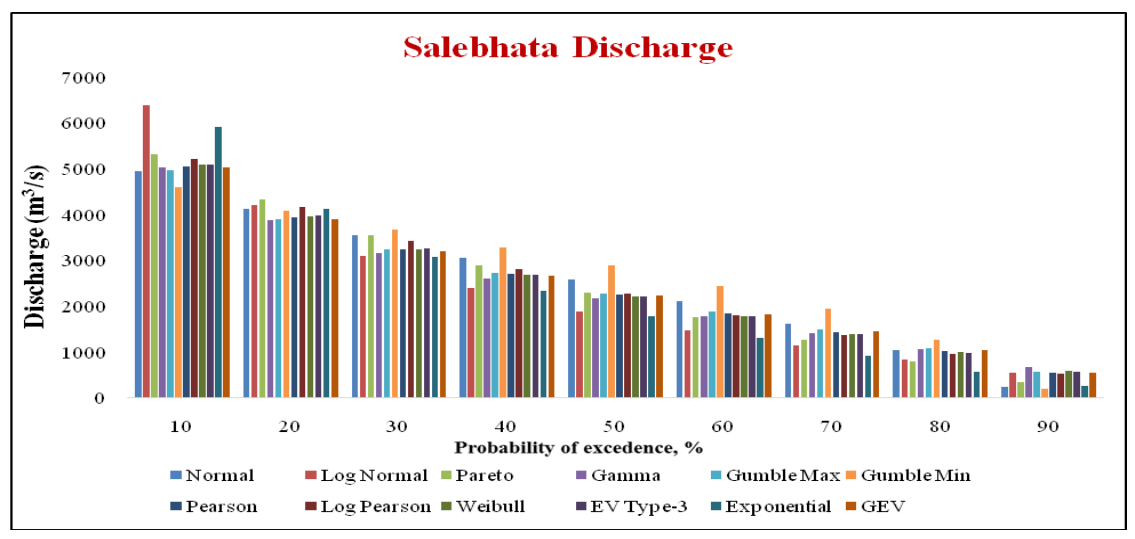


Fig.5 Variation of peak daily discharge at different PE levels by different distributions (Sundargarh)

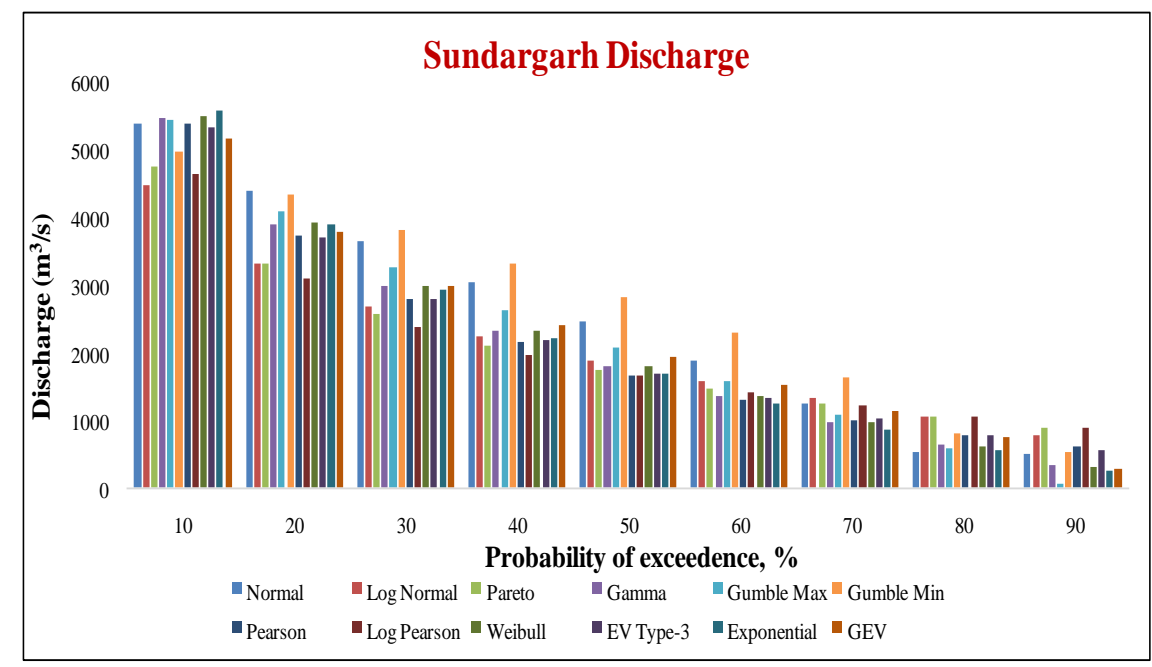

Fig.6 Variation of peak daily discharge at different PE levels by different distributions (Tikarapara)

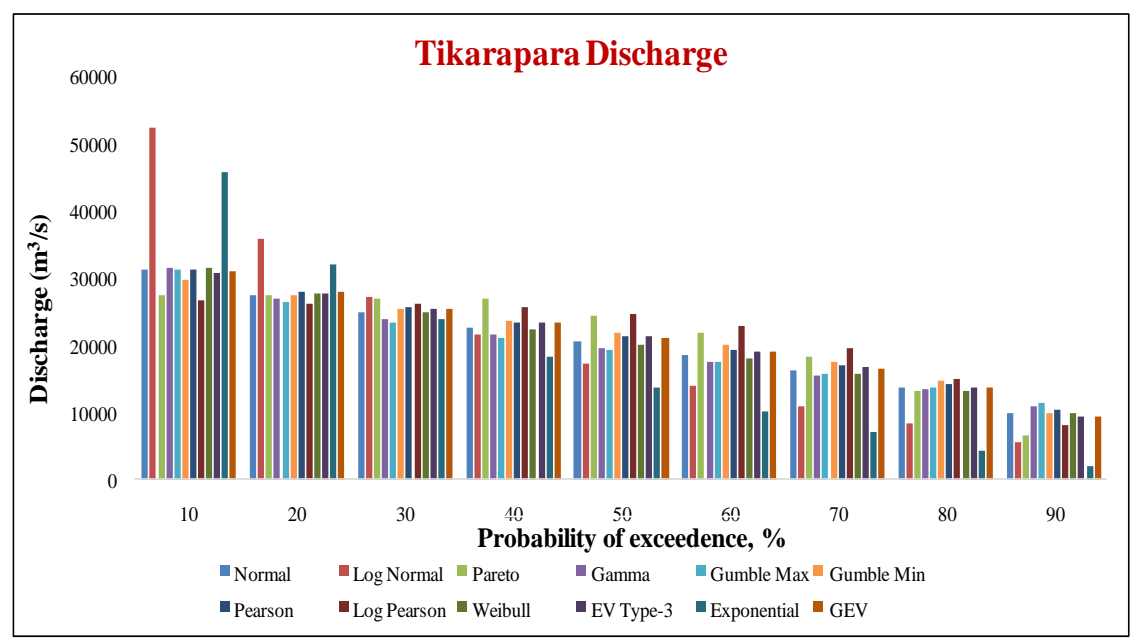

Table 4 shows the daily peak discharge of various stations at different probability of exceedence level by best fit distribution. Sundargarh has the lowest daily discharge value i.e. $4665.19,3106.23,2399.77$, $1968.08,1664.27,1429.99,1235.99,1063.90$ and $894.37 \mathrm{~m}^{3} / \mathrm{s}$ for $10,20,30,40,50,60,70$, 80 and $90 \%$ PE level, respectively which was represented by the data of Table 4 . Data of Table 4 also presents Tikarapara has the highest daily discharge value i.e. 31036.20 , 28057.23, 25648.95, 23449.86, 21297.56, 19068.68, 16615.73, 13675.27 and 9507.86 $\mathrm{m}^{3} / \mathrm{s}$ for $10,20,30,40,50,60,70,80$ and 90\% PE level, respectively.

The probability analysis at different PE levels of discharge helps to know the frequency and magnitude of maximum flood discharge. These data are helpful in design of the 
hydrologic structures like dam, culvert, spillway and bridge etc. Here 10 to $90 \%$ PE levels of discharge are calculated for each station. It is very safe to consider the $10 \% \mathrm{PE}$ level for designing the hydrological structures, but it will be very huge structure and not economical. Though at $90 \%$ PE level, the structure will be economic, but it cannot withstand the maximum flood discharges for which may result in the collapse of the structure. As the recurrence interval of a high flood in the is 5 years (Mishra, 2008), 20\% PE level may be considered for design of hydraulic structures. Values of peak discharge at $20 \%$ PE level as predicted by the best fit distributions for Kantamal, Kesinga, Salebhata, Sundargarh and Tikarapara are 14964.51, 13286.95, 4171.32, 3106.23 and $28057.23 \mathrm{~m}^{3} / \mathrm{s}$, respectively. These values may be considered for design of hydraulic structures in respective stations.

In conclusions from the study it was found that the highest peak discharge for Kantamal is $20000.00 \mathrm{~m}^{3} / \mathrm{s}$, for Kesinga, it is 21192.00 $\mathrm{m}^{3} / \mathrm{s}$, for Salebhata $7916.00 \mathrm{~m}^{3} / \mathrm{s}$, for Sundargarh $10404.00 \mathrm{~m}^{3} / \mathrm{s}$ and for Tikarapara $33800.00 \mathrm{~m}^{3} / \mathrm{s}$ respectively. The values of discharge are found to gradually decrease from $10 \%$ PE level to $90 \%$ PE level for all distributions and for all stations. The peak daily discharge value is the highest at $10 \% \mathrm{PE}$ level and the lowest in 90\% PE level for each station. The best fit probability distribution for discharge are found to be Generalised Pareto in Kantamal and Kesinga station, LogPearson in Salebhata and Sundargarh station and Generalised Extreme Value in Tikarapara station. The recurrence interval of a high flood in the Mahanadi is 5 years for which $20 \%$ PE level may be considered for design of hydraulic structures. Values of peak discharge at $20 \%$ PE level as predicted by the best fit distributions for Kantamal, Kesinga, Salebhata, Sundargarh and Tikarapara are 14964.51, 13286.95, 4171.32, 3106.23 and
$28057.23 \mathrm{~m}^{3} / \mathrm{s}$, respectively. These values may be considered for design of hydraulic structures in respective stations.

\section{References}

Abida H and Ellouze M. 2007. Probability distribution of flood flows in Tunisia, Hydrology and Earth System Sciences Discussions, 4: 957-981.

Adeboye OB and Alatise MO. 2007. Performance of Probability Distributions and Plotting Positions in Estimating the Flood of River Osun at Apoje Sub-basin, Nigeria, Agricultural Engineering International: the CIGR Journal, 9: 1-21.

Deb S and Choudhury P. 2015. Estimation of T-year flood at A.P. ghat station in Barak River, Assam, India, Journal of Civil Engineering and Environmental Technology, 2(8): 640-643.

Ewemoje TA and Ewemooje OS. 2011. Best distribution and plotting positions of daily maximum flood estimation at Ona river in Ogun-Oshun river basin, Nigeria, Agricultural Engineering International: CIGR Journal, 13(3): 111.

Garba H, Ismail A and Tsoho1 U. 2013. Fitting probability distribution functions to discharge variability of Kaduna River, International Journal of Modern Engineering Research (IJMER), 3(5): 2848-2852.

Karim MA and Chowdhury JU. 2009. A comparison of four distributions used in flood frequency analysis in Bangladesh, Hydrological Sciences Journal, 55-66.

Khan M. 2013. Frequency analysis of flood flow at Garudeshwar station in Narmada River, Gujarat, India, Universal Journal of Environmental Research and Technology, 3(6): 677684. 
Khatua S K; Panigrahi B; Paul, J C.2014.Hydrological design of contour bund and contour trench in Khalikani watershed of Odisha. Journal of Soil \& Water Conservation, Vol. 13(2): 112-117.

Khosravi G, Majidil A and Nohegar A. 2012. Determination of suitable probability distribution for annual mean and peak discharges estimation (case study: Minab river- Barantin Gage, Iran), International Journal of Probability and Statistics, 1(5): 160-163.

Laogue K M; Green R E. 1991. Statistical and graphical methods for evaluating solute transport models. Journal of Contaminant Hydrology, Vol. 7: 5173.

Lee C. 2005. Application of rainfall frequency analysis on studying rainfall distribution characteristics of ChiaNan plain area in Southern Taiwan, Journal of Crop, Environment and Bioinformatics, 2: 31-38.

Mishra N. 2008. Macroscale Hydrological Modelling and Impact of landcover change on streamflows of the Mahanadi River Basin, unpublished M.Tech thesis, Indian Institute of Remote Sensing (National Remote Sensing Agency), Dehradhun.

Olofintoye OO, Sule BF and Salami AW. 2009. Best-fit probability distribution model for peak daily rainfall of selected cities in Nigeria, New York Science Journal, 2(3): 1-12.

Panigrahi B; Panigrahi K. 2014.Analysis of daily maximum rainfall for hydrological design of small scale water harvesting structure. Journal of Applied Hydrology. Vol. XXVII, No. (1-4), 28-41.

Panigrahi B; Panigrahi K. 2016. Engineering Hydrology. New India Publishing Agency, New Delhi, pp. 667.

Panigrahi, B; Panda, S.N. 2003. Field test of a soil water balance simulation model, Agricultural Water Management, 58, 223-240.

Solomon O and Prince O. 2013. Flood frequency analysis of Osse river using Gumbel's distribution, Civil and Environmental Research, 3(10): 5559.

Tao DQ, Nguyen VT and Bourque A. 2002. On selection of probability distributions for representing extreme precipitations in Southern Quebec, Annual Conference of the Canadian Society for Civil Engineering, 1-8.

Topaloglu F. 2002. Determining suitable probability distribution models for flow and precipitation series of the Seyhan river basin, Turk Journal of Agriculture, 26: 189 - 194.

Vivekanandan N. 2015. Frequency analysis of annual maximum flood discharge using method of moments and maximum likelihood method of Gamma and Extreme Value family of probability distributions, International Journal of Mathematics and Computational Science, 1(3): 141-146.

How to cite this article:

Panigrahi, B., Dipsika Paramjita, M. Giri and Paul, J. C. 2020. Frequency Analysis for Prediction of Maximum Flood Discharge in Mahanadi River Basin. Int.J.Curr.Microbiol.App.Sci. 9(08): 3626-3639. doi: https://doi.org/10.20546/ijcmas.2020.908.418 